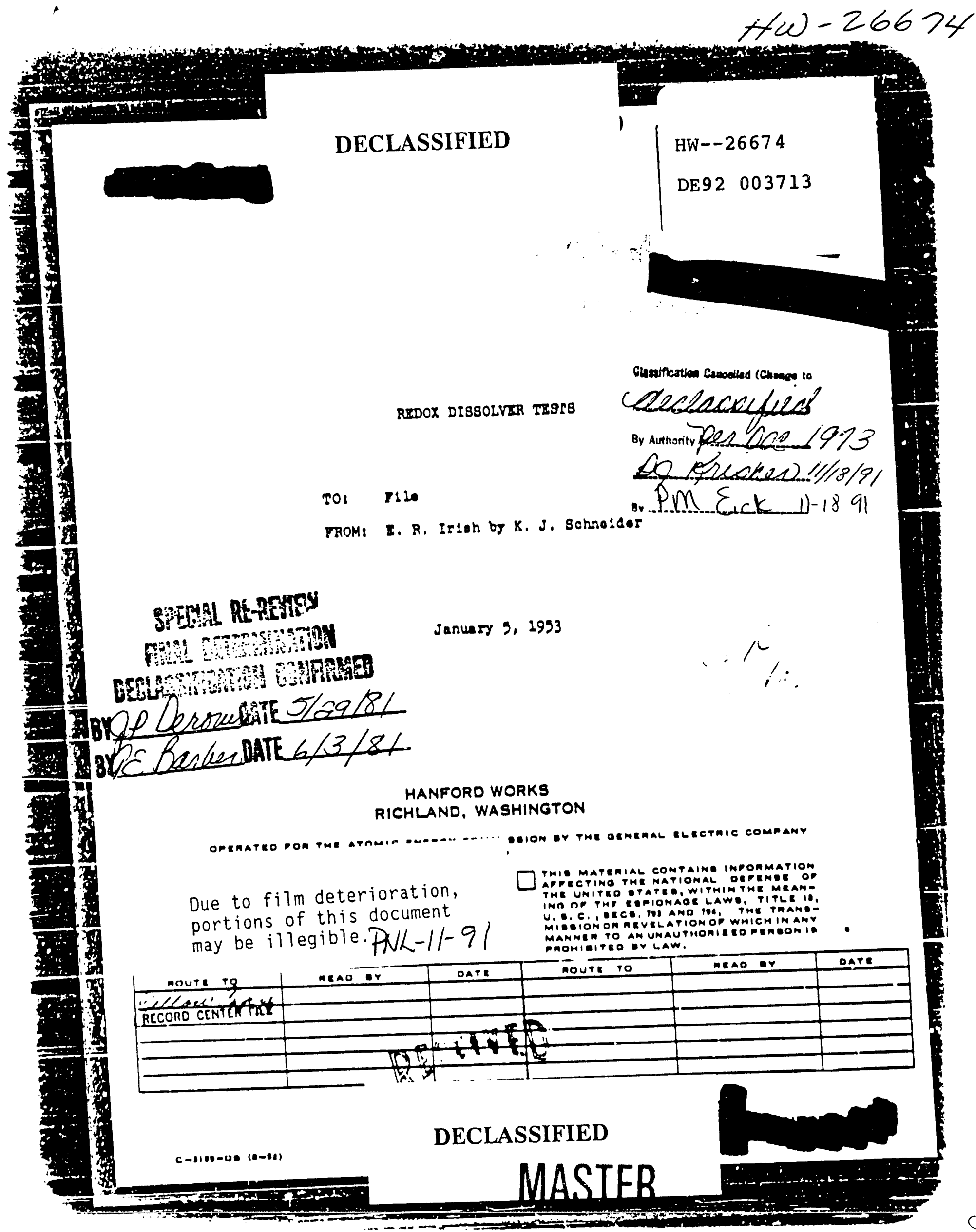




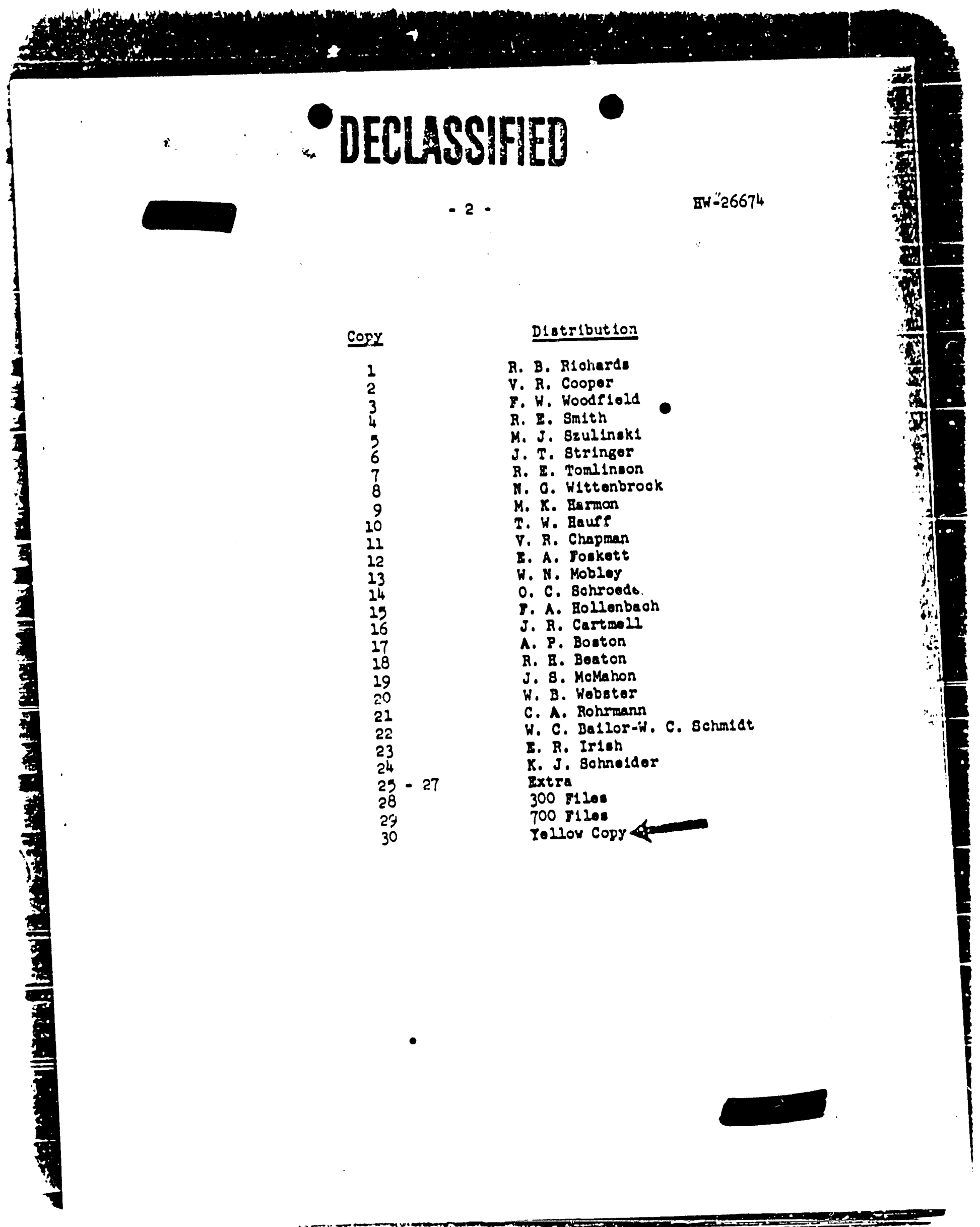




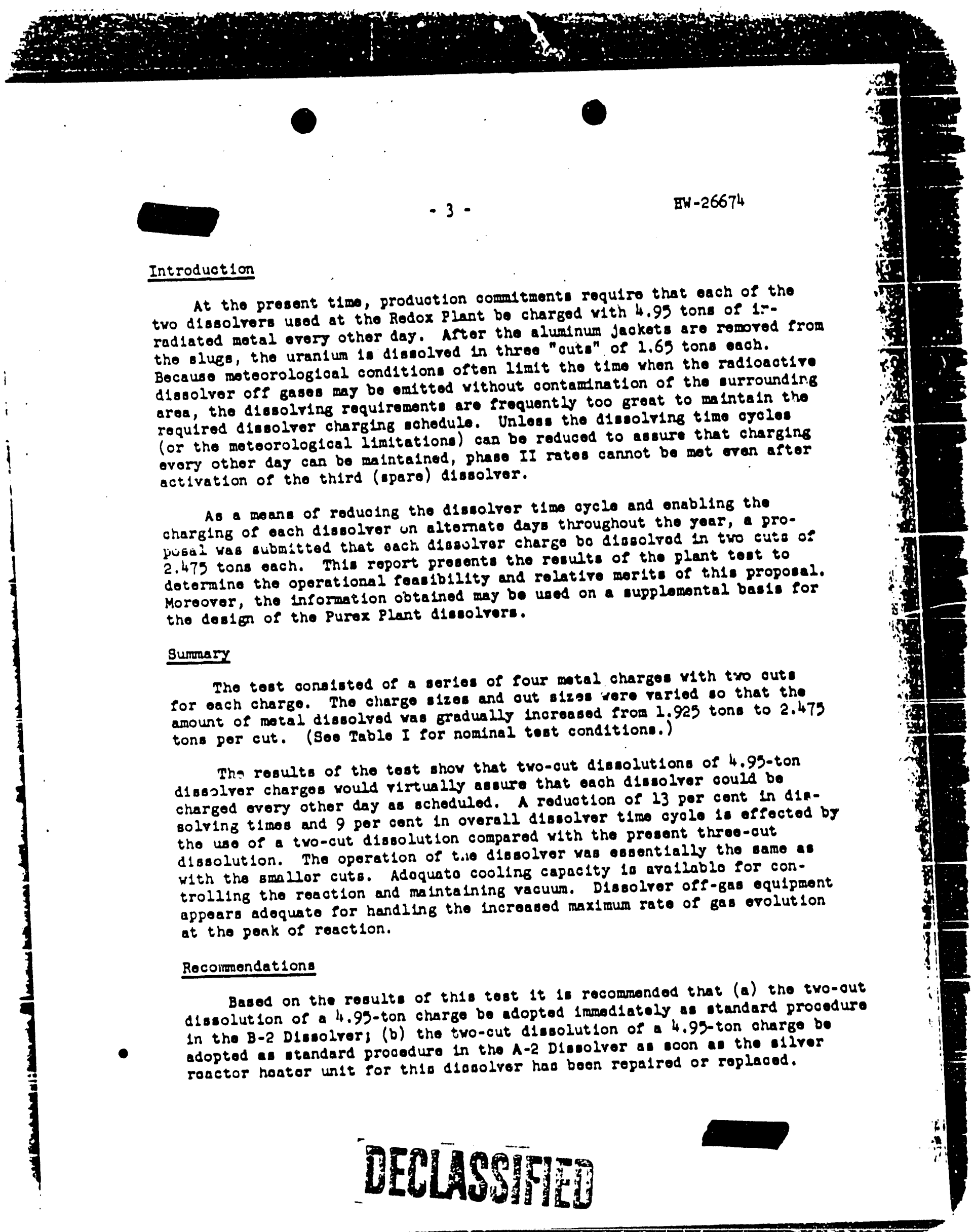




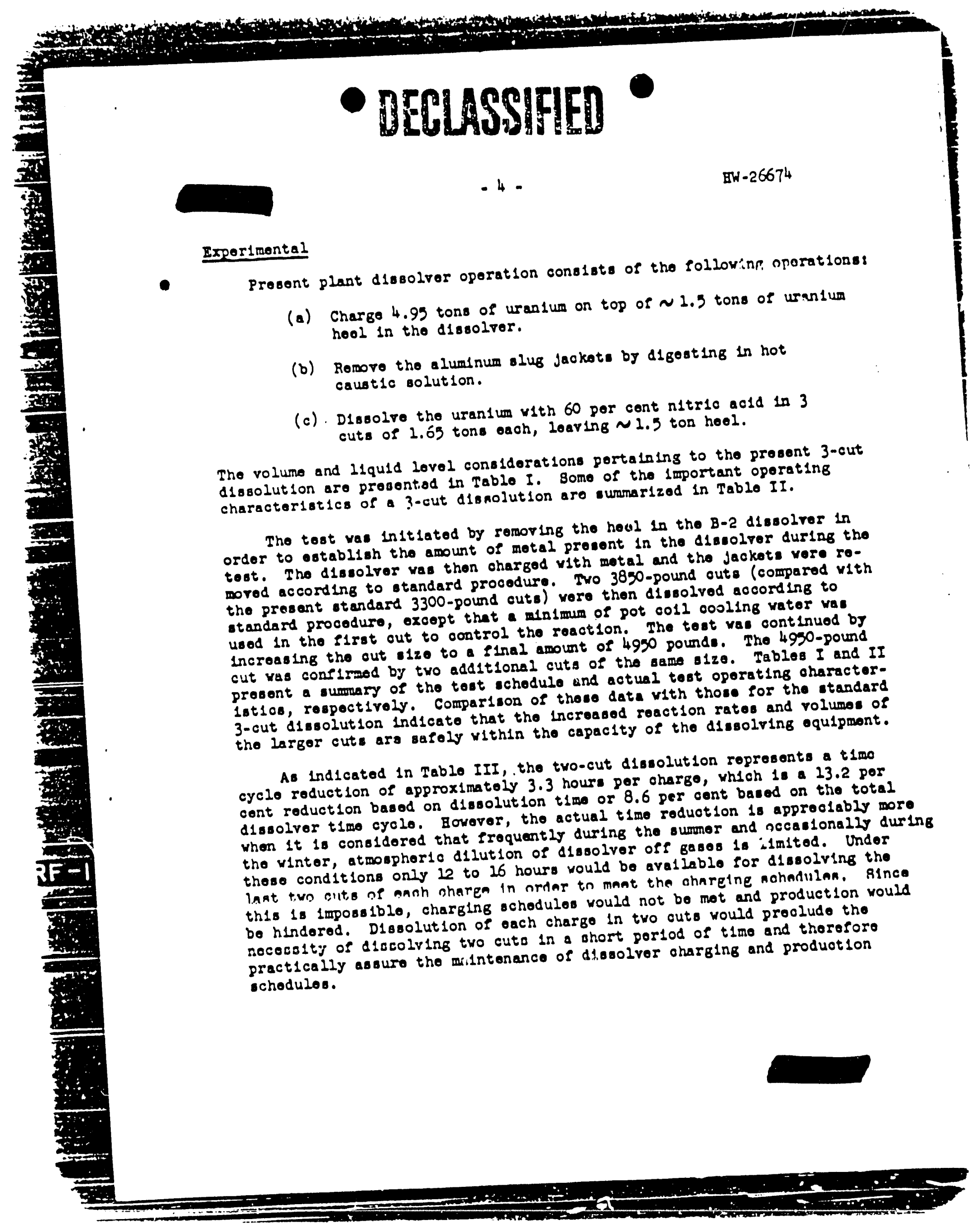




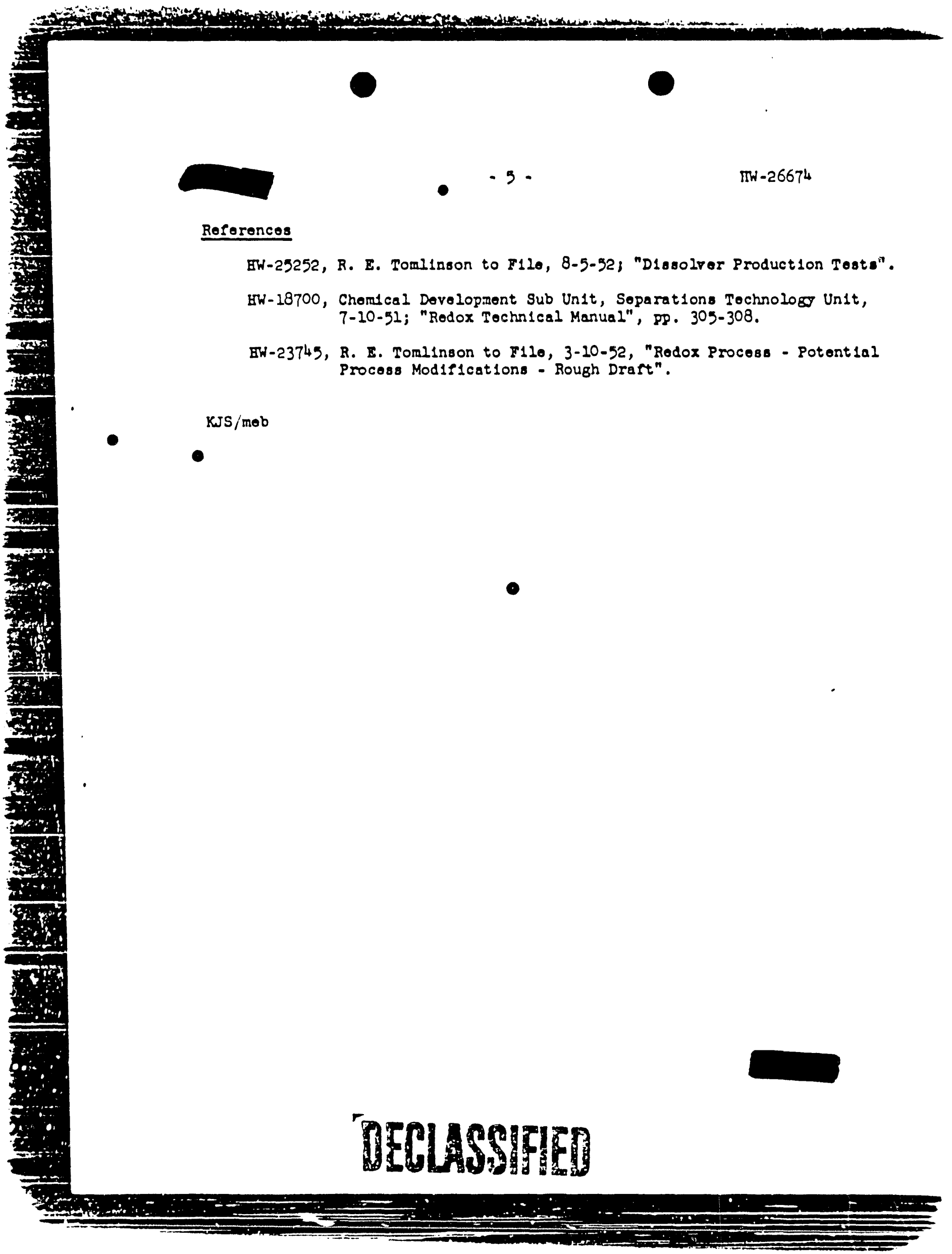




\section{- DECLASSIFEE}

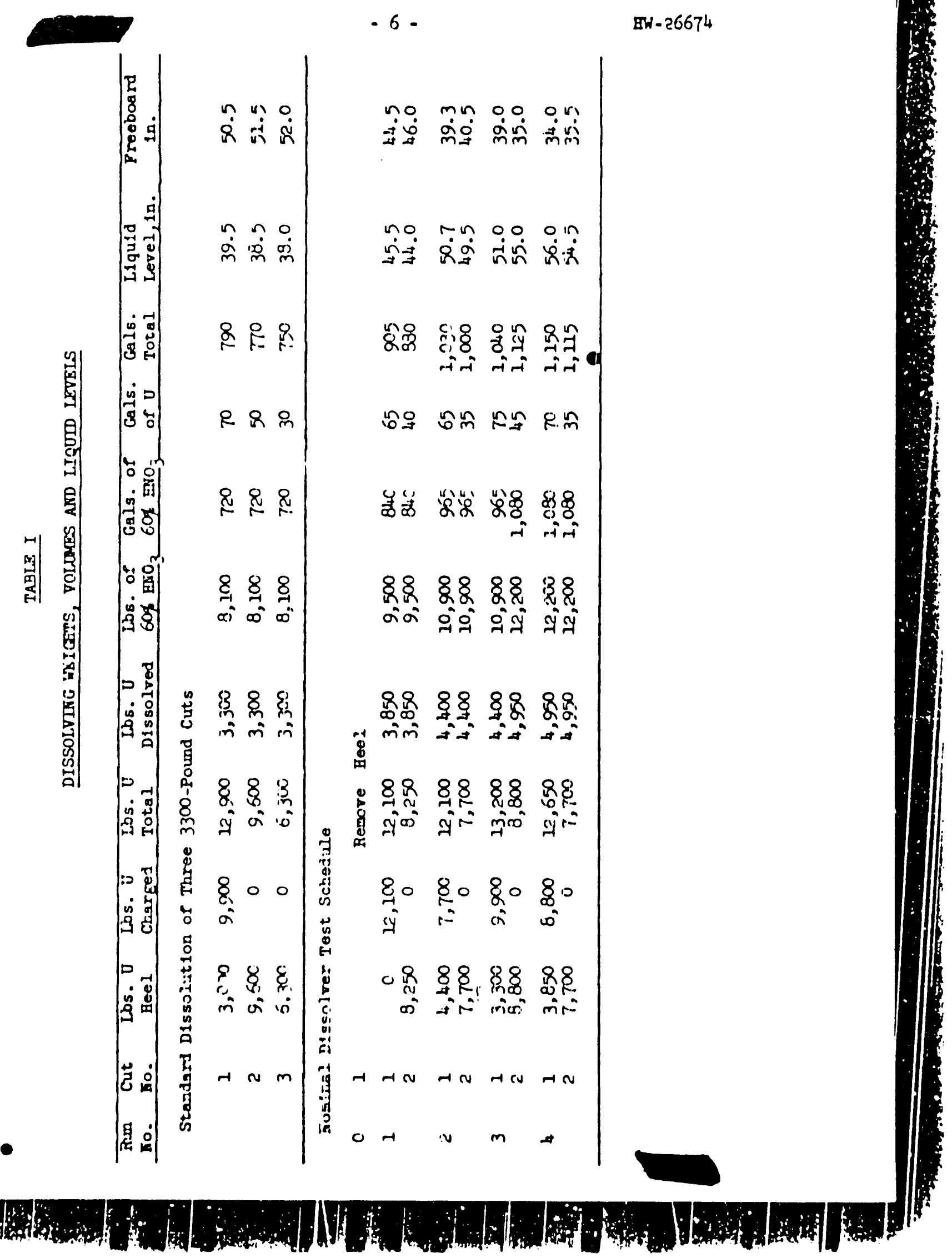




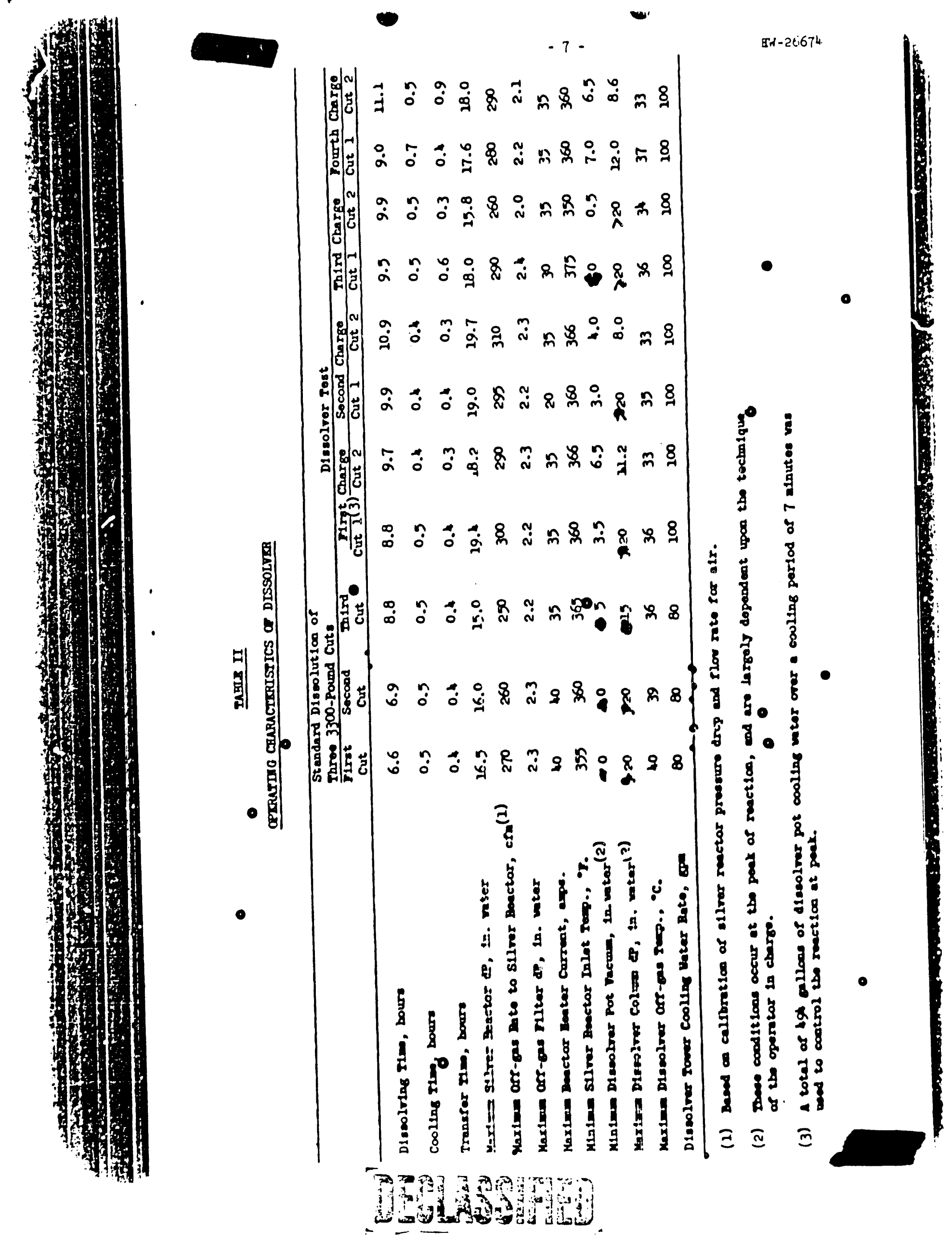




\section{- DELLASSFIED -}

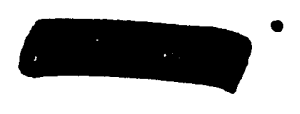

$-3-0$

$\pi w-2.6674$

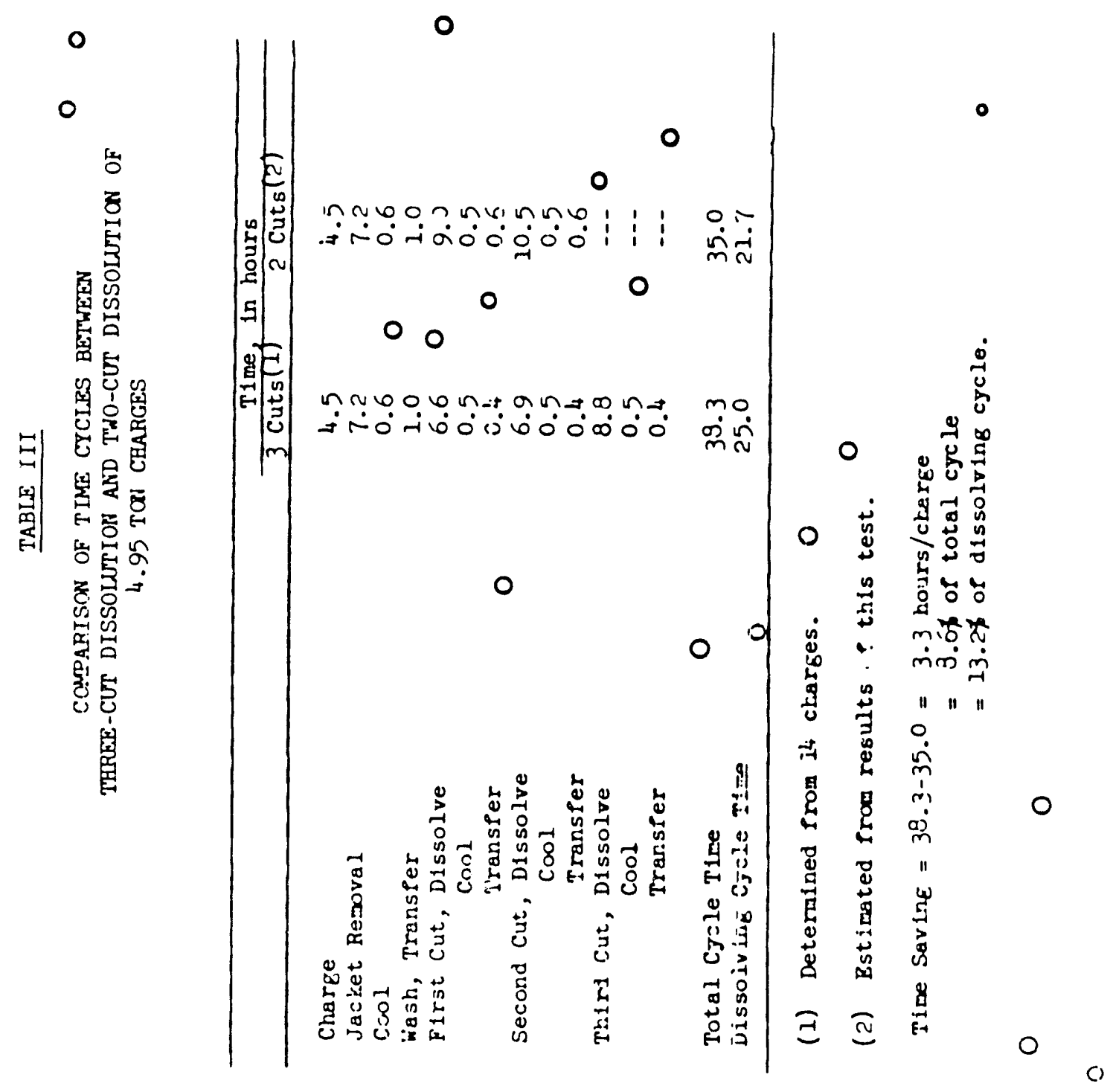

0 

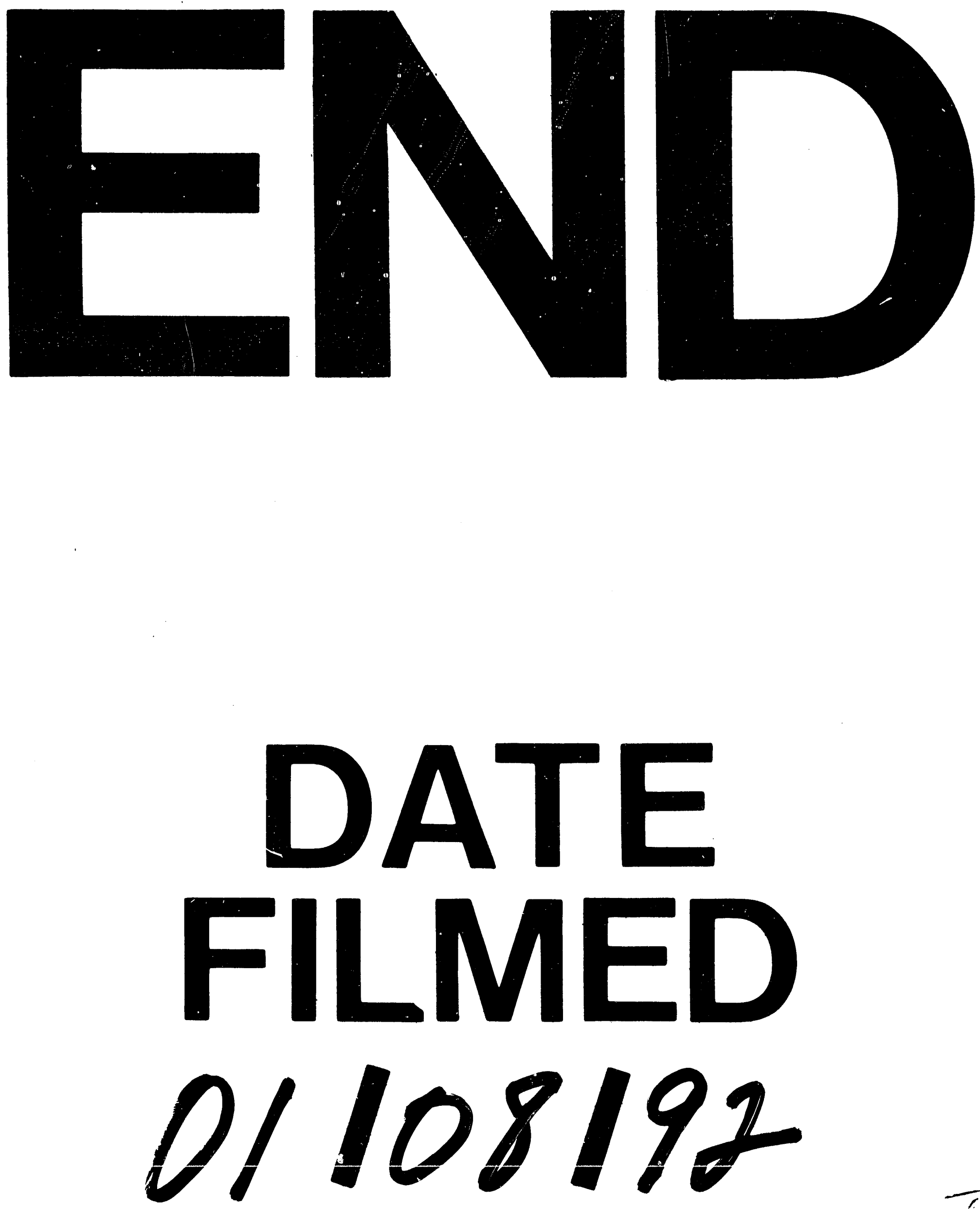
